\title{
A Common Fixed Point Result in Cone Metric Spaces
}

\author{
K. Prudhvi \\ Department of Mathematics, University College of Science, Saifabad, Osmania University, India
}

Copyright $(2016$ by authors, all rights reserved. Authors agree that this article remains permanently open access under the terms of the Creative Commons Attribution License 4.0 International License

\begin{abstract}
In this paper, we study the existence of coincidence points and common fixed point theorem for three self - mappings in cone metric spaces and relaxing the completeness of the space. This result extends and improves the results of M. Abbas and B. E. Rhoades [M. Abbas and B. E. Rhoades, Fixed and periodic point results in cone metric spaces, Appl. Math. Lett., 22(2009) 511-515] who proved fixed point theorems for two self-mappings without assuming commutativity conditions in cone metric spaces and using the completeness of the space.
\end{abstract}

Keywords Fixed Point, Cone Metric Space, Coincidence Point

\section{Introduction}

Ordered Banach spaces, normal cones and topical functions have applications in optimization theory is one of the motivation for research in ordered linear metric spaces (see, e.g. [6], [7]). In 2007, cone metric space was introduced by Huang and Zhang [5] which a generalization of metric space into cone metric space replacing the set of real numbers by an ordered Banach space and obtained some fixed point theorems in this cone metric space. Later on, many authors are inspired with this cone metric space and studied Huang and Zhang [5] fixed point theorems and extended to different contractive conditions (see e.g. [1-4, 8]). Recently, M. Abbas and B. E. Rhoades [2] obtained some fixed point theorems in cone metric spaces for two self-maps without using the commutativity conditions. The aim of this paper, we study the existence of coincidence points and common fixed point theorem for three self- maps in cone metric spaces and relaxing the completeness of the space, which is an extension of the results of M. Abbas and B. E. Rhoades [2].

\section{Preliminaries}

We recall some definitions and properties of cone metric spaces in [5].

\subsection{Definition}

Let $E$ be a real Banach space and $P$ a subset of $E$. The set $P$ is called a cone if and only if:

(a). $\mathrm{P}$ is closed, non-empty and $\mathrm{P} \neq\{0\}$;

(b). $a, b \in \mathbb{R}, a, b \geq 0, x, y \in P$ implies $a x+b y \in P$;

(c). $\mathrm{x} \in \mathrm{P}$ and $-\mathrm{x} \in \mathrm{P}$ implies $\mathrm{x}=0$.

\subsection{Definition}

Let $\mathrm{P}$ be a cone in a Banach space $\mathrm{E}$, define partial ordering ' $\leq$ ' with respect to $\mathrm{P}$ by $\mathrm{x} \leq \mathrm{y}$ if and only if $\mathrm{y}-\mathrm{x} \in \mathrm{P}$. We shall write $\mathrm{x}<\mathrm{y}$ to indicate $\mathrm{x} \leq \mathrm{y}$ but $\mathrm{x} \neq \mathrm{y}$ while $\mathrm{x}<<\mathrm{y}$ will stand for $y-x \in$ int $P$, where int $P$ denotes the interior of the set $\mathrm{P}$. This cone $\mathrm{P}$ is called an order cone.

\subsection{Definition}

Let $\mathrm{E}$ be a Banach space and $\mathrm{P} \subset \mathrm{E}$ be an order cone. The order cone $\mathrm{P}$ is called normal if there exists $\mathrm{L}>0$ such that for all $x, y \in E$,

$$
0 \leq \mathrm{x} \leq \mathrm{y} \text { implies }\|\mathrm{x}\| \leq \mathrm{L}\|\mathrm{y}\| .
$$

The least positive number $\mathrm{L}$ satisfying the above inequality is called the normal constant of $\mathrm{P}$.

\subsection{Definition}

Let $X$ be a nonempty set of E. Suppose that the map d: $X$ $x \mathrm{X} \rightarrow$ E satisfies:

(d1) $0 \leq \mathrm{d}(\mathrm{x}, \mathrm{y})$ for all $\mathrm{x}, \mathrm{y} \in \mathrm{X}$ and $\mathrm{d}(\mathrm{x}, \mathrm{y})=0$ if and only if $\mathrm{x}=\mathrm{y}$;

(d2) $d(x, y)=d(y, x)$ for all $x, y \in X$;

(d3) $d(x, y) \leq d(x, z)+d(y, z)$ for all $x, y, z \in X$.

Then $d$ is called a cone metric on $X$ and $(X, d)$ is called a cone metric space.

It is clear that the concept of a cone metric space is more general than that of a metric space.

\section{5. Example [5]}

Let $\mathrm{E}=\mathbb{R}^{2}, \mathrm{P}=\{(\mathrm{x}, \mathrm{y}) \in \mathrm{E}$ such that $: \mathrm{x}, \mathrm{y} \geq 0\} \subset \mathrm{R}^{2}, \mathrm{X}=\mathrm{R}$ and $\mathrm{d}: \mathrm{X} \times \mathrm{X} \rightarrow \mathrm{E}$ such that $\mathrm{d}(\mathrm{x}, \mathrm{y})=(|\mathrm{x}-\mathrm{y}|, \alpha|\mathrm{x}-\mathrm{y}|)$, 
where $\alpha \geq 0$ is a constant. Then $(\mathrm{X}, \mathrm{d})$ is a cone metric space.

\subsection{Definition}

Let $(X, d)$ be a cone metric space. We say that $\left\{x_{n}\right\}$ is a Cauchy sequence if for every $\mathrm{c}$ in $\mathrm{E}$ with $\mathrm{c}>>0$, there is a natural number $\mathrm{N}$ such that for all $\mathrm{n}, \mathrm{m}>\mathrm{N}, \mathrm{d}\left(\mathrm{x}_{\mathrm{n}}, \mathrm{x}_{\mathrm{m}}\right)<<\mathrm{c}$.

\subsection{Definition}

Let $(X, d)$ be a cone metric space. We say that $\left\{X_{n}\right\}$ is a convergent sequence if for any $\mathrm{c}>>0$, there is an $\mathrm{N}$ such that for all $\mathrm{n}>\mathrm{N}, \mathrm{d}\left(\mathrm{x}_{\mathrm{n}, \mathrm{x}}\right)<<\mathrm{c}$, for some fixed $\mathrm{x}$ in $\mathrm{X}$. We denote this $x_{n} \rightarrow x($ as $n \rightarrow \infty)$.

The space $(\mathrm{X}, \mathrm{d})$ is called a complete cone metric space if every Cauchy sequence is convergent ([5]).

\subsection{Definition [1]}

Let $f, g: X \rightarrow X$ be mappings. If $w=f(z)=g(z)$ for some $z \in X$, then $z$ is called a coincidence point of $f$ and $g$, and $w$ is called a point of coincidence of $f$ and $g$.

\subsection{Definition [3]}

The mappings $\mathrm{f}, \mathrm{g}: \mathrm{X} \rightarrow \mathrm{X}$ are said to be weakly compatible if for every $\mathrm{x} \in \mathrm{X}$, holds:

$$
f(g(x))=g(f(x)) \text { whenever } f(x)=g(x) .
$$

\subsection{Lemma}

Let be a non-empty set $\mathrm{X}$ and the mappings $\mathrm{f}, \mathrm{g}$ and $\mathrm{h}$ have a unique point of coincidence point win X. If $(f, h)$ and $(g, h)$ are weakly compatible self- maps of $\mathrm{X}$, then $\mathrm{f}, \mathrm{g}$ and $\mathrm{h}$ have a unique common fixed point.

\section{Main Results}

In this section, we obtain coincidence points and common fixed point theorem for three self-maps in cone metric spaces.

We have adopted the technique which is used in [3].

Let $(\mathrm{X}, \mathrm{d})$ be a cone metric space and $\mathrm{f}, \mathrm{g}$ and $\mathrm{h}$ be self-mappings of $X$ such that $f(X) \cup g(X) \subseteq h(X)$. Suppose $\mathrm{x}_{0} \in \mathrm{X}$ and $\mathrm{x}_{1} \in \mathrm{X}$ is chosen such that $\mathrm{hx}_{1}=\mathrm{fx}_{0}$ and $\mathrm{x}_{2} \in \mathrm{X}$ is chosen such that $\mathrm{hx}_{2}=\mathrm{gx}_{1}$. Continuing in this way, the sequence $\left\{\mathrm{hx}_{\mathrm{n}}\right\}$ such that

$$
\begin{gathered}
\mathrm{y}_{2 \mathrm{n}}=\mathrm{hx}_{2 \mathrm{n}+1}=\mathrm{fx}_{2 \mathrm{n}}, \\
\mathrm{y}_{2 \mathrm{n}+1}=\mathrm{hx}_{2 \mathrm{n}+2}=\mathrm{gx}_{2 \mathrm{n}+1}, \mathrm{n}=0,1,2, \ldots
\end{gathered}
$$

is called a (f-g)-sequence with initial point $\mathrm{x}_{0}$.

\subsection{Proposition}

Let $(\mathrm{X}, \mathrm{d})$ be a cone metric space, and $\mathrm{P}$ be a normal cone with normal constant $\mathrm{L}$. Suppose that the mappings $\mathrm{f}, \mathrm{g}$ and $\mathrm{h}$ are three self-maps of $X$ such that $f(X) \cup g(X) \subseteq h(X)$ satisfying

$\mathrm{d}(\mathrm{fx}, \mathrm{gy}) \leq \alpha \mathrm{d}(\mathrm{hx}, \mathrm{hy})+\beta[\mathrm{d}(\mathrm{hx}, \mathrm{fx})+\mathrm{d}(\mathrm{hy}, \mathrm{gy})]+\gamma[\mathrm{d}(\mathrm{hx}, \mathrm{gy})+$ $+\mathrm{d}(\mathrm{hy}, \mathrm{fx})]$

for all $\mathrm{x}, \mathrm{y} \in \mathrm{X}$, where $\alpha, \beta, \gamma \geq 0$ and $\alpha+2 \beta+2 \gamma<1$.

Then every (f-g)-sequence with initial point $\mathrm{x}_{0} \in \mathrm{X}$ is a Cauchy sequence.

Proof. Suppose $\left\{\mathrm{hx}_{\mathrm{n}}\right\}$ is a (f-g) sequence with initial point $\mathrm{x}_{0}$. Assume $h \mathrm{x}_{\mathrm{n}} \neq h \mathrm{x}_{\mathrm{n}+1}$ for all $\mathrm{n} \in \mathrm{N}$, then $\mathrm{x}_{\mathrm{n}} \neq \mathrm{x}_{\mathrm{n}+1}$ for all $\mathrm{n}$.

Using (1) we have

$$
\begin{aligned}
& d\left(y_{2 n}, y_{2 n+1}\right)=d\left(h x_{2 n+1}, h x_{2 n+2}\right) \\
& =\mathrm{d}\left(\mathrm{fx}_{2 \mathrm{n}}, \mathrm{gx}_{2 \mathrm{n}+1}\right) \\
& \leq \alpha \mathrm{d}\left(\mathrm{hx}_{2 \mathrm{n}}, \mathrm{hx}_{2 \mathrm{n}+1}\right)+\beta\left[\mathrm{d}\left(\mathrm{hx}_{2 \mathrm{n}}, \mathrm{fx}_{2 \mathrm{n}}\right)\right. \\
& \left.+\mathrm{d}\left(\mathrm{hx}_{2 \mathrm{n}+1}, \mathrm{gx}_{2 \mathrm{n}+1}\right)\right]+\gamma\left[\mathrm{d}\left(\mathrm{hx}_{2 \mathrm{n}}, \mathrm{gx}_{2 \mathrm{n}+1}\right)+\mathrm{d}\left(\mathrm{hx}_{2 \mathrm{n}+1}, \mathrm{fx}_{2 \mathrm{n}}\right)\right] \\
& \leq \alpha \mathrm{d}\left(\mathrm{hx}_{2 \mathrm{n}}, \mathrm{hx}_{2 \mathrm{n}+1}\right)+\beta\left[\mathrm{d}\left(\mathrm{hx}_{2 \mathrm{n}}, \mathrm{hx}_{2 \mathrm{n}+1}\right)\right. \\
& \left.+\mathrm{d}\left(\mathrm{hx}_{2 \mathrm{n}+1}, \mathrm{hx}_{2 \mathrm{n}+2}\right)\right]+\gamma\left[\mathrm{d}\left(\mathrm{hx}_{2 \mathrm{n}}, \mathrm{hx}_{2 \mathrm{n}+2}\right)+\mathrm{d}\left(\mathrm{hx}_{2 \mathrm{n}+1}\right. \text {, }\right. \\
& \left.\mathrm{hx}_{2 \mathrm{n}+1}\right) \text { ] } \\
& \leq(\alpha+\beta) d\left(h_{2 n}, h x_{2 n+1}\right)+\beta d\left(h x_{2 n+1}, h x_{2 n+2}\right)+\gamma \\
& {\left[\mathrm{d}\left(\mathrm{hx}_{2 \mathrm{n}}, \mathrm{hx}_{2 \mathrm{n}+1}\right)+\mathrm{d}\left(\mathrm{hx}_{2 \mathrm{n}+1}, \mathrm{hx}_{2 \mathrm{n}+2}\right)\right]} \\
& \leq(\alpha+\beta+\gamma) \mathrm{d}\left(\mathrm{hx}_{2 \mathrm{n}}, \mathrm{hx}_{2 \mathrm{n}+1}\right)+(\beta+\gamma) \mathrm{d}\left(\mathrm{hx}_{2 \mathrm{n}+1}, \mathrm{hx}_{2 \mathrm{n}+2}\right) \text {. } \\
& \leq(\alpha+\beta+\gamma) d\left(y_{2 n-1}, y_{2 n}\right)+(\beta+\gamma) d\left(y_{2 n}, y_{2 n+1}\right) \text {. }
\end{aligned}
$$

Hence,

$$
\begin{aligned}
1-(\beta+\gamma) d\left(y_{2 n}, y_{2 n+1}\right) & \leq(\alpha+\beta+\gamma) d\left(y_{2 n-1}, y_{2 n}\right) . \\
d\left(y_{2 n}, y_{2 n+1}\right) & \leq(\alpha+\beta+\gamma) / 1-(\beta+\gamma) d\left(y_{2 n-1}, y_{2 n}\right) .
\end{aligned}
$$

Let $\lambda=(\alpha+\beta+\gamma) / 1-(\beta+\gamma)$. Then $\lambda<1$.

$$
d\left(y_{2 n}, y_{2 n+1}\right) \leq \lambda d\left(y_{2 n}, y_{2 n-1}\right)
$$

where, $\lambda<1$.

Similarly, it can be shown that

$$
d\left(y_{2 n+1}, y_{2 n+2}\right) \leq \lambda d\left(y_{2 n}, y_{2 n+1}\right) .
$$

Therefore for all $\mathrm{n}$,

$$
d\left(y_{n+1}, y_{n+2}\right) \leq \lambda d\left(y_{n}, y_{n+1}\right) \leq \ldots \leq \lambda^{n+1} d\left(y_{0}, y_{1}\right) .
$$

Now for any $m>n$,

$$
\begin{aligned}
\mathrm{d}\left(\mathrm{y}_{\mathrm{n}}, \mathrm{y}_{\mathrm{m}}\right) & \leq \mathrm{d}\left(\mathrm{y}_{\mathrm{n}}, \mathrm{y}_{\mathrm{n}+1}\right)+\mathrm{d}\left(\mathrm{y}_{\mathrm{n}+1}, \mathrm{y}_{\mathrm{n}+2}\right)+\ldots+\mathrm{d}\left(\mathrm{y}_{\mathrm{m}-1}, \mathrm{y}_{\mathrm{m}}\right) . \\
& \leq\left(\lambda^{\mathrm{n}}+\lambda^{\mathrm{n}+1}+\ldots+\lambda^{\mathrm{m}-1}\right) \mathrm{d}\left(\mathrm{y}_{1}, \mathrm{y}_{0}\right) . \\
& \leq \lambda^{\mathrm{n}} / 1-\lambda \mathrm{d}\left(\mathrm{y}_{1}, \mathrm{y}_{0}\right) .
\end{aligned}
$$

From (2.3), we have

$$
\left\|\mathrm{d}\left(\mathrm{y}_{\mathrm{n}}, \mathrm{y}_{\mathrm{m}}\right)\right\| \leq \lambda^{\mathrm{n}} / 1-\lambda \mathrm{L}\left\|\mathrm{d}\left(\mathrm{y}_{1}, \mathrm{y}_{0}\right)\right\| .
$$

Since $\lambda<1, \lambda^{\mathrm{n}} / 1-\lambda \rightarrow 0$ as $\mathrm{n} \rightarrow \infty$.

Which implies that

$$
\mathrm{d}\left(\mathrm{y}_{\mathrm{n}}, \mathrm{y}_{\mathrm{m}}\right) \rightarrow 0 \text { as } \mathrm{n}, \mathrm{m} \rightarrow \infty \text {. }
$$

Hence, $\left\{\mathrm{y}_{\mathrm{n}}\right\}$ is a Cauchy sequence, where $\left\{\mathrm{y}_{\mathrm{n}}\right\}=\left\{\mathrm{hx}_{\mathrm{n}}\right\}$.

\subsection{Theorem}

Let $(\mathrm{X}, \mathrm{d})$ be a e cone metric space, and $\mathrm{P}$ be a normal cone 
with normal constant $\mathrm{K}$. Suppose that the mappings $\mathrm{f}, \mathrm{g}$ and $\mathrm{h}$ are three self- maps of $X$ such that $f(X) \cup g(X) \subseteq h(X)$ satisfying

$d(f x, g y) \leq \alpha d(h x, h y)+\beta[d(h x, f x)+d(h y, g y)]+\gamma[d(h x$, gy) + d(hy, fx $)]$

for all $\mathrm{x}, \mathrm{y} \in \mathrm{X}$, where $\alpha, \beta, \gamma \geq 0$ and $\alpha+2 \beta+2 \gamma<1$.

If $f(X) \cup g(X)$ or $h(X)$ is a complete subspace of $X$, then $f$, $\mathrm{g}$ and $\mathrm{h}$ have a unique point of coincidence. Moreover, if $(\mathrm{f}, \mathrm{h})$ and $(\mathrm{g}, \mathrm{h})$ are weakly compatible, then $\mathrm{f}, \mathrm{g}$ and $\mathrm{h}$ have a unique common fixed point.

Proof. Since, $h(X)$ is complete subspace of $X$. And since, by the proposition $2.1 \mathrm{a}$ (f-g) sequence $\left\{\mathrm{hx}_{\mathrm{n}}\right\}$ with the initial point $\mathrm{x}_{0}$ is a Cauchy sequence, there exists $\mathrm{u}, \mathrm{v} \in \mathrm{X}$ such that $\mathrm{hx}_{\mathrm{n}} \rightarrow \mathrm{v}=\mathrm{hu}$.

The same argument holds if $f(X) \cup g(X)$ is a complete subspace of $X$ with $v \in f(X) \cup g(X)$.

From (3) and triangle inequality

$d(h u, f u) \leq d\left(h u, h x_{2 n}\right)+d\left(h x_{2 n}, f u\right)$

$\leq \mathrm{d}\left(\mathrm{hu}, \mathrm{hx}_{2 \mathrm{n}}\right)+\mathrm{d}\left(\mathrm{fu}, \mathrm{gx}_{2 \mathrm{n}-1}\right)$

$\leq \mathrm{d}\left(\mathrm{v}, \mathrm{hx}_{2 \mathrm{n}}\right)+\alpha \mathrm{d}(\mathrm{hu}$,

$\left.\mathrm{hx}_{2 \mathrm{n}-1}\right)+\beta\left[\mathrm{d}(\mathrm{hu}, \mathrm{fu})+\mathrm{d}\left(\mathrm{hx}_{2 \mathrm{n}-1}, \mathrm{gx}_{2 \mathrm{n}-1}\right)\right]+\gamma[\mathrm{d}(\mathrm{hu}$,

$\left.\left.\mathrm{gx}_{2 \mathrm{n}-1}\right)+\mathrm{d}\left(\mathrm{hx}_{2 \mathrm{n}-1}, \mathrm{fu}\right)\right]$

$\leq \mathrm{d}\left(\mathrm{v}, \mathrm{hx}_{2 \mathrm{n}}\right)+\alpha \mathrm{d}\left(\mathrm{v}, \mathrm{hx}_{2 \mathrm{n}-1}\right)+\beta\left[\mathrm{d}(\mathrm{hu}, \mathrm{fu})+\mathrm{d}\left(\mathrm{hx}_{2 \mathrm{n}-1}\right.\right.$,

$\left.\mathrm{hu})+\mathrm{d}\left(\mathrm{hu}, \mathrm{gx}_{2 \mathrm{n}-1}\right)\right]+\gamma\left[\mathrm{d}\left(\mathrm{hu}, \mathrm{hx}_{2 \mathrm{n}}\right)+\mathrm{d}\left(\mathrm{hx}_{2 \mathrm{n}-1, \mathrm{hu}}\right)+\right.$

$\mathrm{d}(\mathrm{hu}, \mathrm{fu})]$

$\leq \mathrm{d}\left(\mathrm{v}, \mathrm{hx}_{2 \mathrm{n}}\right)+\alpha \mathrm{d}\left(\mathrm{v}, \mathrm{hx}_{2 \mathrm{n}-1}\right)+\beta[\mathrm{d}(\mathrm{hu}, \mathrm{fu})+$

$\left.\mathrm{d}\left(\mathrm{hx}_{2 \mathrm{n}-1}, \mathrm{v}\right)+\mathrm{d}\left(\mathrm{v}, \mathrm{gx}_{2 \mathrm{n}-1}\right)\right]+\gamma\left[\mathrm{d}\left(\mathrm{v}, \mathrm{hx}_{2 \mathrm{n}}\right)+\mathrm{d}\left(\mathrm{hx}_{2 \mathrm{n}-1, \mathrm{v}} \mathrm{v}\right)+\right.$

$\mathrm{d}(\mathrm{hu}, \mathrm{fu})]$

$\leq(1+\beta+\gamma) \mathrm{d}\left(\mathrm{v}, \mathrm{hx}_{2 \mathrm{n}}\right)+(\alpha+\beta+\gamma) \mathrm{d}\left(\mathrm{hx}_{2 \mathrm{n}-1}, \mathrm{v}\right)+(\beta+\gamma) \mathrm{d}(\mathrm{hu}$, $\mathrm{fu})$.

$1-(\beta+\gamma) d(h u, f u) \leq(1+\beta+\gamma) d\left(v, h x_{2 n}\right)+(\alpha+\beta+\gamma) d\left(h x_{2 n-1}, v\right)$.

$\mathrm{d}(\mathrm{hu}, \mathrm{fu}) \leq(1+\beta+\gamma) / 1-(\beta+\gamma) \mathrm{d}\left(\mathrm{v}, \mathrm{hx}_{2 \mathrm{n}}\right)+(\alpha+\beta+\gamma) /$

$$
1-(\beta+\gamma) d\left(h_{2 n-1}, v\right) \text {. }
$$

Let $\lambda_{1}=(1+\beta+\gamma) / 1-(\beta+\gamma)$ and $\lambda_{2}=(\alpha+\beta+\gamma) / 1-(\beta+\gamma)$.

$\mathrm{d}(\mathrm{hu}, \mathrm{fu}) \leq \lambda_{1} \mathrm{~d}\left(\mathrm{v}, \mathrm{hx}_{2 \mathrm{n}}\right)+\lambda_{2} \mathrm{~d}\left(\mathrm{hx}_{2 \mathrm{n}-1}, \mathrm{v}\right)$.

Which from (2.3) implies that

$\|\mathrm{d}(\mathrm{hu}, \mathrm{fu})\| \leq \mathrm{L}\left\{\lambda_{1}\left\|\mathrm{~d}\left(\mathrm{v}, \mathrm{hx}_{2 \mathrm{n}}\right)\right\|+\lambda_{2}\left\|\mathrm{~d}\left(\mathrm{hx}_{2 \mathrm{n}-1}, \mathrm{v}\right)\right\|\right\}$.

Now the right hand side of the above approaches to zero as $\mathrm{n} \rightarrow \infty$.

Hence,

$$
\|\mathrm{d}(\mathrm{hu}, \mathrm{fu})\|=0 \text { and } \mathrm{fu}=\mathrm{hu}(=\mathrm{v}) .
$$

Similarly, by using the inequality

$\mathrm{d}(\mathrm{hu}, \mathrm{gu}) \leq \mathrm{d}\left(\mathrm{hu}, \mathrm{hx}_{2 \mathrm{n}+1}\right)+\mathrm{d}\left(\mathrm{hx}_{2 \mathrm{n}+1}, g u\right)$.

We can show that

$$
\mathrm{hu}=\mathrm{gu}(=\mathrm{v}) .
$$

Thus, $v=h u=f u=g u$ and hence we conclude that $v$ is a point of coincidence of $f, g$ and $h$.
Now we show that the point of coincidence is unique.

Assume that there is another point of coincidence $\mathrm{v}^{*}$ in $\mathrm{X}$ such that

$$
\mathrm{v}^{*}=\mathrm{fu}^{*}=\mathrm{gu}^{*}=\mathrm{hu} \mathrm{u}^{*} \text { for some } \mathrm{u}^{*} \in \mathrm{X} .
$$

It is easy to see that using (3) that

$$
\begin{aligned}
& \mathrm{d}\left(\mathrm{v}, \mathrm{v}^{*}\right)=\mathrm{d}\left(\mathrm{fu}, \mathrm{gu}^{*}\right) \\
& \leq \alpha \mathrm{d}\left(\mathrm{hu}, \mathrm{hu} \mathrm{u}^{*}\right)+\beta\left[\mathrm{d}(\mathrm{hu}, \mathrm{fu})+\mathrm{d}\left(\mathrm{hu}^{*}, \mathrm{gu}^{*}\right)\right]+\gamma[\mathrm{d}(\mathrm{hu}, \\
& \left.\left.\mathrm{gu}^{*}\right)+\mathrm{d}\left(\mathrm{hu}^{*}, \mathrm{fu}\right)\right] \\
& \leq \alpha d\left(v, v^{*}\right)+\beta\left[d(v, v)+d\left(u^{*}, u^{*}\right)\right]+\gamma\left[d\left(u, u^{*}\right)+d\left(u^{*}, u\right)\right] \\
& (1-\alpha) d\left(v, v^{*}\right) \leq 2 \gamma d\left(u^{*}, u\right) \\
& d\left(v, v^{*}\right) \leq 2 \gamma /(1-\alpha) d\left(u^{*}, u\right) \text {. }
\end{aligned}
$$

Putting, $b=2 \gamma /(1-\alpha)<1$.

$$
\mathrm{d}\left(\mathrm{v}, \mathrm{v}^{*}\right) \leq \mathrm{b} d\left(\mathrm{u}^{*}, \mathrm{u}\right) .
$$

Since, $\alpha+2 \gamma<1$, then $v=v^{*}$.

Since, (f, h) and $(g, h)$ are weakly compatible by assumption $\mathrm{v}$ is the unique point of coincidence of $f, g$ and $h$, then by the Lemma $(2.10)$ we get that $\mathrm{v}$ is the unique common fixed point off, $g$ and $h$.

\subsection{Remark}

If we choose $\mathrm{h}=\mathrm{I}_{\mathrm{X}}$ is an identity map in the above Theorem 3.2., then we deduce the following Theorem.

\subsection{Theorem}

Let $(\mathrm{X}, \mathrm{d})$ be a cone metric space, and $\mathrm{P}$ be a normal cone with normal constant $\mathrm{K}$. Suppose that the mappings $\mathrm{f}$ and $\mathrm{g}$ are two self- maps of $\mathrm{X}$ satisfying

$$
d(f x, g y) \leq \alpha d(x, y)+\beta[d(x, f x)+d(y, g y)]+\gamma[d(x, g y)+d(y, f x)]
$$

for all $\mathrm{x}, \mathrm{y} \in \mathrm{X}$, where $\alpha, \beta, \gamma \geq 0$ and $\alpha+2 \beta+2 \gamma<1$.

If $f(X)$ or $g(X)$ is a complete subspace of $X$, then $f$ and $g$ have a unique point of coincidence. Moreover, if $f$ and $g$ are weakly compatible, then $\mathrm{f}$ and $\mathrm{g}$ have a unique common fixed point.

\subsection{Remark}

In the above Theorem 3.4., if $\mathrm{X}$ is a complete cone metric space and without commutativity, then as an immediate consequence of Theorem 3.4., we obtain Theorem 2.1 of [2].

\section{Conclusions}

We have extended the results of [2] without assuming the completeness in the space.

\section{Acknowledgements}

We are very grateful to experts for their appropriate and constructive suggestions to improve this manuscript. 


\section{REFERENCES}

[1] M. Abbas and G. Jungck, Common fixed point results for non-commuting mappings without continuity in cone metric spaces. J. Math. Anal. Appl., 341(2008) 416-420.

[2] M. Abbas and B. E. Rhoades, Fixed and periodic point results in cone metric spaces, Appl. Math. Lett. 22(2009) 511-515.

[3] M. Arshad, A. Azam, P. Vetro, Some common fixed point results on cone metric spaces, Fixed Point Theory Appl., (2009)11, Article ID 493965.

[4] C. Di Bari and P. Vetro, $\varphi$-pairs and common fixed points in cone metric spaces, Rendiconti del Circolo Mathematico di Palermo, Vol. 57(2008) 279-285.

[5] L. G. Huang, X. Zhang, Cone metric spaces and fixed point theorems of contractive mappings, J. Math. Anal. Appl., 332(2) (2007)1468-1476.

[6] H. Mohebi, Topical functions and their properties in a class of ordered Banach spaces, Part II of the Book "Continuous optimization, Current Trends and Modern Applications", Springer, 2005, 343-361.

[7] H. Mohebi and H. Sadeghi, A. M. Rubinow, Best approximations in a class of normed spaces with star-shapes cone, Numer. Funct. Anal. Optim, 27 (3-4) (2006), 411-436.

[8] S. Rezapour and R. Hamlbarani, Some notes on the paper cone metric spaces and fixed point theorem of contractive mappings, J. Math. Anal. Appl. 345(2008), 719-724. 